\title{
HOLD-TIME STUDY FOR PHARMACEUTICAL TABLET DURING MANUFACTURING PROCESS: AN INNOVATIVE STEP
}

\author{
SAYEED SHAZIYA Y*, GOYAL ANJU \\ Department of Bhupal Nobles' Institute of Pharmaceutical Sciences, Udaipur, Rajasthan, India. Email: shaziya.sy@gmail.com
}

Received: 19 September 2017, Revised and Accepted: 17 November 2017

ABSTRACT

Objective: The objective of the study was to ensure that intermediates and the bulk product can be held without any significant adverse effect on the quality of the material till next step of processing. Such a holding period should be based on data. Studies should not be extended to find the edge of failure for holding.

Method: Samples are put away in same natural conditions as in manufacturing/storage. After establishing a sampling plan required sample amount based on the batch size is ascertained, the intervals and tests are to be performed. Samples are kept in a storage container and tested. Results are contrasted and the underlying benchmark information of the control test. Hold-time study data shall give the assurance the maximum allowable hold times for bulk and in-process drug products. In general, one lot can be used for validating hold times if any irregularity comes, results were observed then another two lots can be used for this investigation.

Conclusion: Each manufacturing stage shelf life can be determined depending on the hold-time study results. If the hold-time samples are passing at 60 -day time point, then the shelf life of the specific stage can be considered up to 45 days.

Keywords: Pharmaceutical manufacturing, Hold-time process, Tablet manufacturing, Coated tablets, Shelf life, Quality of the pharmaceutical product. (c) 2018 The Authors. Published by Innovare Academic Sciences Pvt Ltd. This is an open access article under the CC BY license (http://creativecommons. org/licenses/by/4. 0/) DOI: http://dx.doi.org/10.22159/ajpcr.2018.v11i1.22669

\section{INTRODUCTION}

Hold-time studies help ensure the quality of the pharmaceutical product which does not deteriorate significantly during the hold time and establish the time limits for holding the materials at various stages of the production. Hold-time must be taken into consideration before the marketing of a manufactured product. The risk evaluation of changes in processes, equipment, storage conditions, and starting, or packaging materials ought to incorporate an appraisal of whether additionally; hold-time studies ought to be performed. Although for products which have been already marketed retrospective risk-based, hold-time studies should be performed. The plan of the examination must reflect the holding time at each phase of the tablet production. To approve the hold time under the specific hold-time condition, results attained should be within the confinement of acceptance criteria all through the hold time.

Good manufacturing practices require that courses of action ought to be ensured that the dispensed raw materials and packaging materials, in-process products, bulk, and finished products are put away under appropriate conditions. Storage arrangement should not have a harmful effect on the accompanying preparation, strength, stability, quality or quality of raw materials, in-process products, and finished products before final packaging. Most acceptable holding periods should in this way be set up to guarantee that in-process and bulk item can be held, pending the next processing step, without delivering results beyond the acceptance criteria for the quality of the material. In general, in-process and bulk products should not be put away past the setup hold time [1]

Hold-time studies might be built up for bulk and intermediate drug products and furthermore accompanied by improvement on pilot scale batches or during scale-up, and ought to be confirmed during process validation of commercial scale processing. Promote information to justify the hold time can be gathered as a feature of an examination of a deviation which happened during production [2].
Studies should be led to give information to help bulk holding times for in-process or intermediate materials. For a stable medication item, it is generally accepted that no formal examination is required if intermediate materials are held for under 30 days. For unstable products or materials that should be held longer than 30 days, stability studies are essential to demonstrate the holding times do not influence the quality of the intermediate products [3].

\section{Hold-time study protocol in tablet manufacturing process}

In hold-time studies initially, three batches of a similar product should be considered. Assess the manufacturing procedure of the product and separate the basic phases of the manufacturing process on the basis of time length required for the specific handling stage and the effect of time with reference to environmental condition and storage conditions [4].

- After finishing of dry blending, the required amount of sample is gathered from 5 distinct positions, i.e., right, left, rear, front, and center portions.

- After completion of drying, the required amount of granules is gathered from 5 distinct positions, i.e., right, left, rear, front, and center portions.

- After the finish of lubrication process, the required amount of lubricated mix is gathered from 11 distinct places of conta blender.

- After completion of compression of the tablets, required amount of sample is gathered from both the sides; right-hand side and left-hand side of the machine at beginning, center, and end of the machine run.

- After consummation of the coating of the tablets, required amount of sample is gathered at beginning, center, and end of the machine run. Composite sample makes after the accumulation of tablet at beginning, center, and end of machine run. Coated tablets should be kept in a controlled condition in well-closed intermediate product container/stainless steel container containing two-fold polythene pack with status mark.

After gathering of samples physical and chemical parameters are considered at various interim, i.e., beginning, $14^{\text {th }}$ day, $30^{\text {th }}$ day, $60^{\text {th }}$ day, and $90^{\text {th }}$ day [5]. 
Table 1: Steps to be considered for coated tablets

\begin{tabular}{ll}
\hline Step & Product \\
\hline Binder preparation to granulation & Granulate \\
Wet granulation to drying & Dried granules \\
Dried granules to lubrication/blending & Lubricated blend \\
Compression to coating & Tablet cores \\
Coating solution to preparation & Coating solution \\
Coating to packing & Bulk coated tablets \\
\hline
\end{tabular}

A written protocol, method or program should be followed, which incorporates, for instance,

- The exercises to be performed.

- Test parameters.

- Acceptance criteria are fitting to the material or product under test.

- To screen and assess the critical process parameters, for example,

- $\quad$ Dry mixing

- Drying

- Lubrication

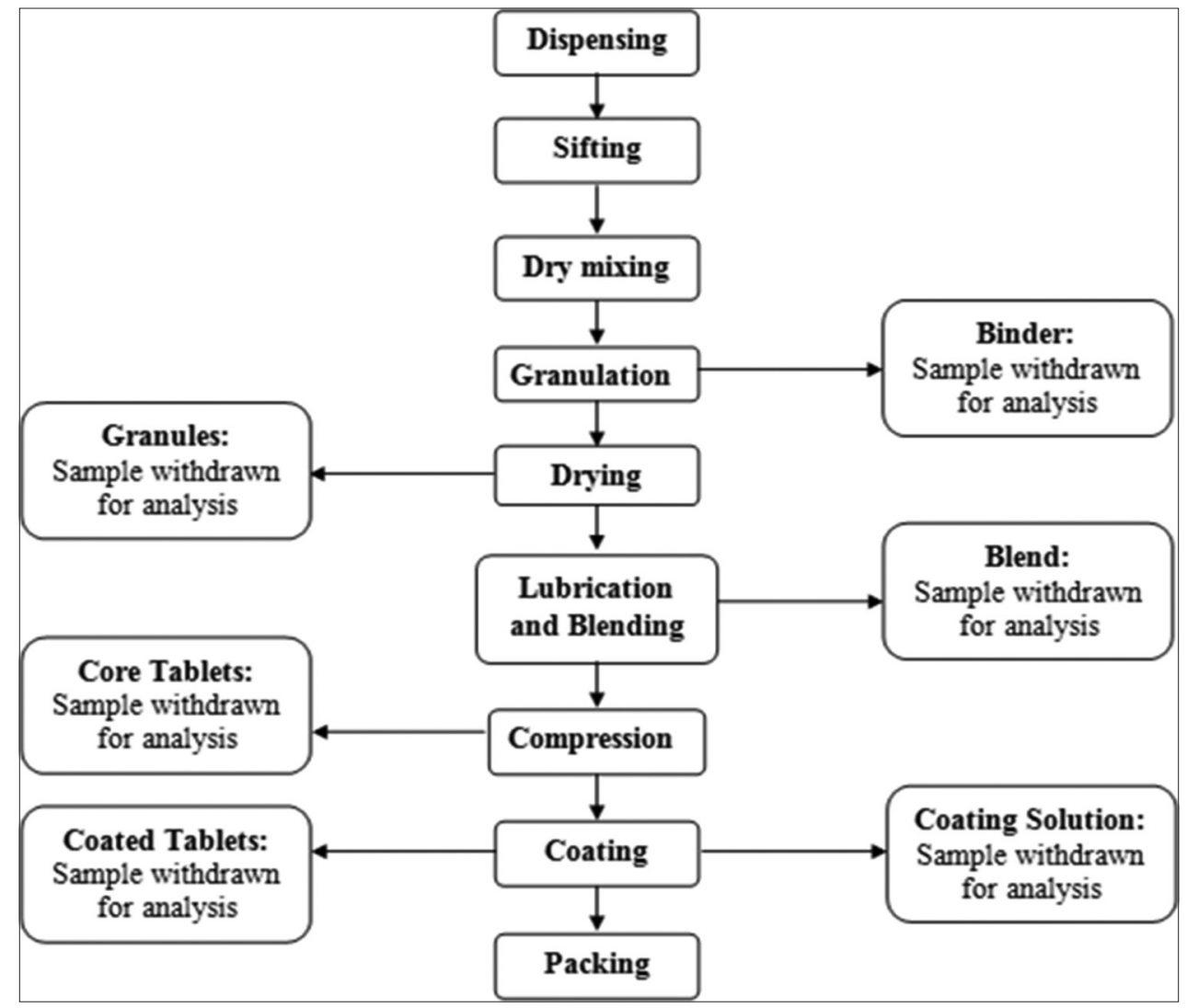

Fig. 1: Hold-time study flow chart in tablet manufacturing process

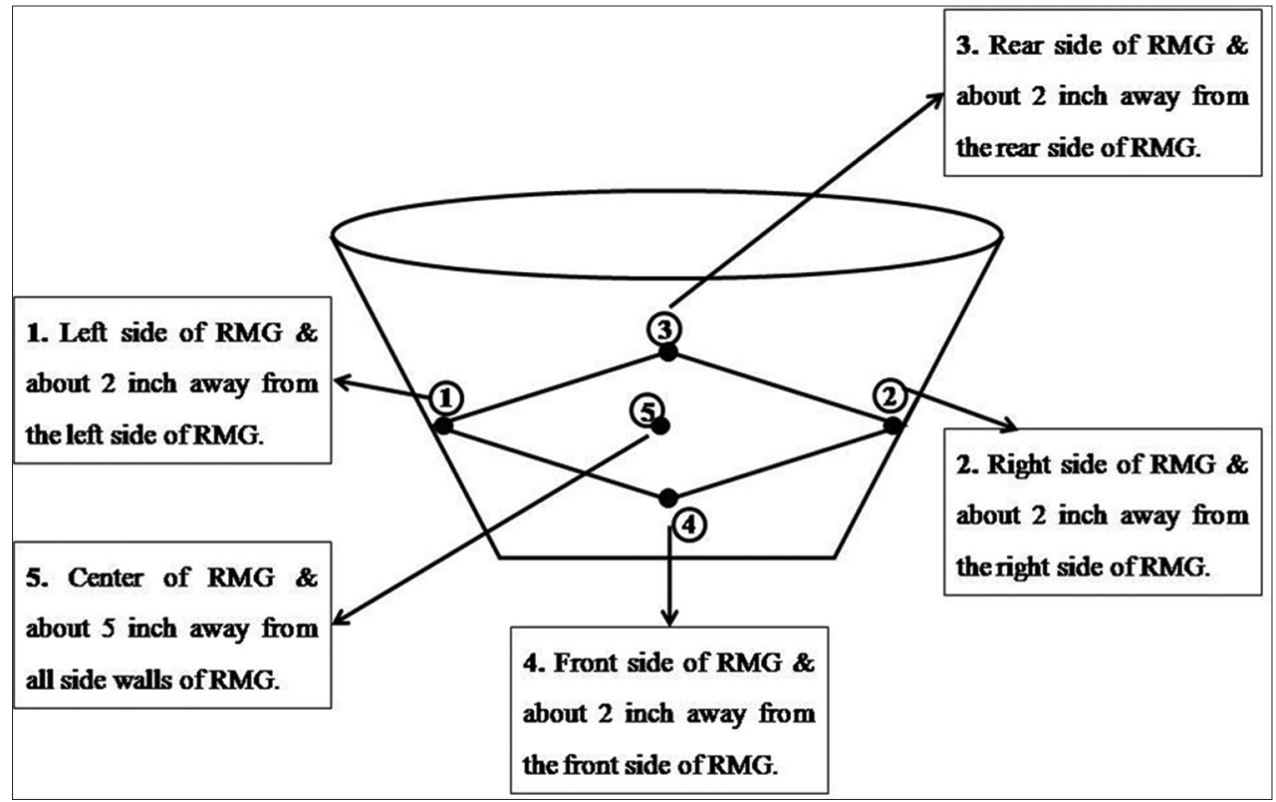

Fig. 2: Sampling points from rapid mixer granulator 
Table 2: Sampling points and sampling strategy in tablet manufacturing process

\begin{tabular}{|c|c|c|c|c|}
\hline Process stage & Processing time & Equipment & Sampling tool & Sampling points \\
\hline $\begin{array}{l}\text { Dry mixing } \\
\text { stage }\end{array}$ & After completion of dry mixing & RMG & Sampling rod/scoop & $01 \times 05=5$ samples [Fig. 2] \\
\hline Drying stage & After completion of drying & $\begin{array}{l}\text { Fluidized bed } \\
\text { dryer }\end{array}$ & Sampling rod & $\begin{array}{l}01 \times 05=5 \text { samples approximately } 5 \mathrm{~g} \text { collected each } \\
\text { from front, rear, left, right, and center }\end{array}$ \\
\hline Lubrication & $\begin{array}{l}\text { After completion of lubrication } \\
\text { process }\end{array}$ & Conta blender & Sampling rod & $01 \times 11=11$ samples [Fig. 3 ] \\
\hline Compression & $\begin{array}{l}\text { After completion of compression } \\
\text { of the tablets }\end{array}$ & $\begin{array}{l}\text { Compression } \\
\text { machine }\end{array}$ & Sampling scoop & $\begin{array}{l}\text { From LHS and RHS, collect sample at start, pool } 1 \\
\text { (pooled tablet samples of } 20 \% \text { and } 40 \% \text { of total } \\
\text { blend compressed), pool } 2 \text { (pooled tablet samples } \\
\text { of } 60 \% \text { and } 80 \% \text { of total blend compressed) and } \\
\text { at the end of compression activity. Mix and make } \\
\text { composite sample }\end{array}$ \\
\hline Coating & $\begin{array}{l}\text { After completion of coating of the } \\
\text { tablets }\end{array}$ & Auto-coater & Sampling scoop & $\begin{array}{l}\text { Take } 3 \text { samples from - one from left top, right middle, } \\
\text { and center bottom portion, respectively }\end{array}$ \\
\hline
\end{tabular}

RHS: Right-hand side, LHS: Left-hand side, RMG: Rapid mixer granulator

Table 3: Stages, tests to be carried out and study time

\begin{tabular}{|c|c|c|}
\hline Stage & Test to be carried out as per specifications & Study time \\
\hline Binder preparation & Microbial counts & Initial and $24 \mathrm{~h}$ \\
\hline Wet granulation to Drying & Microbial counts & Initial, $4 \mathrm{~h}$, and $8 \mathrm{~h}$ \\
\hline Dried granules to & Description, assay, loss on drying & Initial, $8 \mathrm{~h}, 24 \mathrm{~h}$, and $72 \mathrm{~h}$ \\
\hline lubrication/blending & & \\
\hline $\begin{array}{l}\text { Lubrication/blending to } \\
\text { compression }\end{array}$ & $\begin{array}{l}\text { Description, assay, loss on drying, blend uniformity, microbial limits, } \\
\text { bulk/tapped density, particle size }\end{array}$ & Initial, 3 days, and 7 days \\
\hline Compression to coating & $\begin{array}{l}\text { Description, hardness, thickness, friability, disintegration time, } \\
\text { assay, loss on drying, dissolution, degradation products/related } \\
\text { substance and microbial limits }\end{array}$ & Initial, 14 days, 30 days, 60 days, and 90 days \\
\hline $\begin{array}{l}\text { Aqueous coating solution } \\
\text { preparation }\end{array}$ & Microbial counts & Initial, $12 \mathrm{~h}, 24 \mathrm{~h}, 36 \mathrm{~h}$, and $48 \mathrm{~h}$ \\
\hline Coating to packing & $\begin{array}{l}\text { Description, hardness, thickness, friability, disintegration time, assay, } \\
\text { loss on drying, dissolution, degradation products/related substance } \\
\text { and microbial limits }\end{array}$ & Initial, 14 days, 30 days, 60 days, and 90 days \\
\hline
\end{tabular}

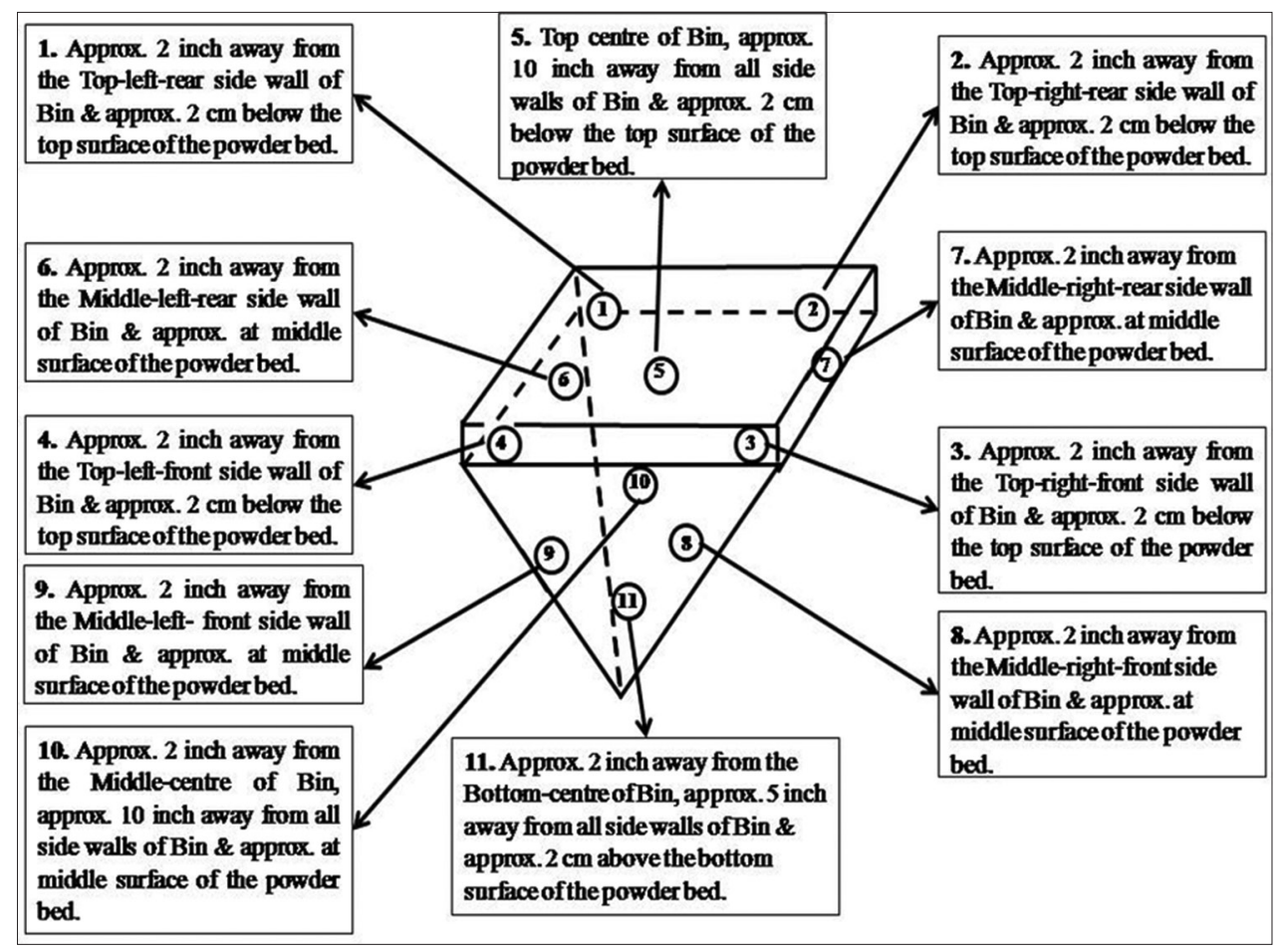

Fig. 3: Sampling points from conta blender 


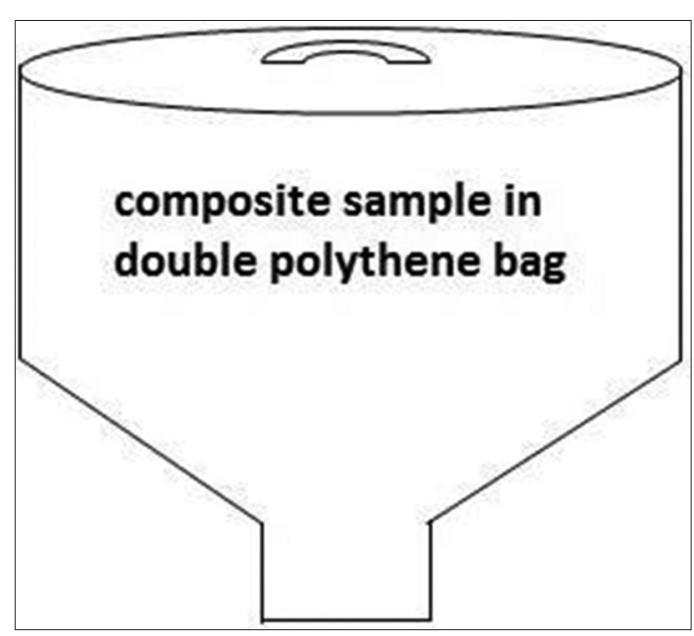

Fig. 4: Samples for hold-time studies withdrawn from IPC/SS container when sample is to be stored in quarantine area at initial, $30^{\text {th }}$ day, $60^{\text {th }}$ day, and $90^{\text {th }}$ day.

- Compression process

- Coating process.

The protocol and report should incorporate the accompanying:

\begin{tabular}{ll}
\hline Title & Acceptance limits \\
Reference number & Frequency of sampling \\
Version & Sampling areas \\
Date & Pooling of samples \\
Objective & Storage conditions \\
Scope & Type of container/closure \\
Responsibility & Methods of analysis \\
Procedure & Results \\
Description of the material or item & Conclusion \\
Sample amounts & Recommendation \\
Sampling strategy and criteria & Signatures and dates \\
\hline
\end{tabular}

This category of tablets arises manufacturing with the following steps, i.e., dispensing, sifting, dry mixing/roll compaction, blending, compression, and packing. Hold study required for this formulation is dry mixing, roll compaction, blending, and un-coated tablets. The required tests and time points are listed in Table 3 and flowchart, hold study requirements are represented in Fig. 1.

- If time length surpasses 90 days before packing then retesting is to be executed.

\section{Precautions}

- Lubricated granules: Lubricated granules should be put away at the controlled condition in well-closed IPC/SS holder containing two-fold polythene sack with status mark. (Fig. 4).

- Compressed tablets: Compressed tablets should be put away in a controlled condition in well-closed IPC/SS container containing two-fold polythene pack with status mark. (Fig. 4).

\section{CONCLUSION}

- This article concentrates mostly on aspects which should be considered in the outline of the hold-time studies during the manufacturing of tablets. Manufacturers should gather logical and reasonable information to display that the dispensed starting materials and packaging materials, intermediate, and bulk products; stay of appropriate quality before handling to the next stage, meet the acceptance criteria and finally the finished product should meet the release specifications.

- In the event that microbial contamination happens where microorganisms enter the product in adequate numbers and if the procedure hold time is sufficiently long, the procedure hold time might be dangerous. This can be limited as an issue if adequate controls are set up to counteract contamination occurring.

- Hold-time studies establish the time limits for holding the materials at various phases of production to assure that the quality of the product does not produce results outside the acceptance criteria during the hold time. The outline of the study should reflect the holding time at each stage.

\section{REFERENCES}

1. Supplementary Guidelines on GMP: Validation, Non-Sterile Process Validation. In: WHO Expert Committee on Specifications for Pharmaceutical Preparations: Forty-Ninth Report. Geneva: WHO; 2015: Annex 3 (WHO Technical Report Series, No. 992).

2. Agalloco JP, Carleton FJ. Validation of Pharmaceutical Processes. $3^{\text {rd }}$ ed. New York: Information Healthcare; 2007. p. 444-6.

3. Pawar DP, Shamkuwar PB, Chavan SS. Hold time study of Cetirizine di hydrochloride lubricated granules. Asian J Pharm Clin Res 2012;5 Suppl 4:234-6.

4. Huma A, Khatri AM, Jain A, Modi R, Pate A. Standard practice of sampling, storage and holding time for pharmaceutical tablet and injection during manufacturing process. Drug Invent Today 2011;3:157-9.

5. Pawar DP, Shamkuwar PB, Hosmani AH. Hold time study for pharmaceutical binders, lubricated granules, compressed tablets, coating suspension and coated tablets during manufacturing process. Pharm Sin 2012;3:300-4. 